\title{
Adhesives and Adhesion Technologies: A Critical Review
}

\section{Srijita Bharti}

Department of Chemistry, Cambridge Institute of Polytechnic, Ranchi, India

\section{Email address:}

bhartisrijita18@gmail.com

\section{To cite this article:}

Srijita Bharti. Adhesives and Adhesion Technologies: A Critical Review. American Journal of Polymer Science and Technology Vol. 4, No. 1, 2018, pp. 36-41. doi: 10.11648/j.ajpst.20180401.13

Received: July 29, 2018; Accepted: August 30, 2018; Published: September 17, 2018

\begin{abstract}
The article critically reviews about adhesives and their various adhesion phenomenons along with their categorization and functions. Benefit and drawbacks of adhesives joining was explained. Requirements for excellent bonding which includes, appropriate selection of adhesive, superior design for joining, surface cleansing, wetting were defined. The review clearly indicates the various theories involved in adhesion are namely mechanical interlocking, electrostatic, diffusion, wetting, chemical bonding, and weak boundary layer. Bond failure modes and their mechanism were elaborated briefly.
\end{abstract}

Keywords: Adhesive, Adhesion Theories, Chemical Bonding, Mechanical Interlocking, Damage Modelling

\section{Introduction}

\subsection{Explanation of Adhesives and Their Bonding Phenomenon}

A material which is used to the articles surfaces for their eternal joint is called an "adhesive" and the process being used is called "adhesive bonding". A material competent to form bonds between two parts where final entity made of two reciprocally joints sections is called adhesive [1]. Adhesion [2] is a condition in which two singular specimen are bonded to each other via seal contact interfacially such as mechanical forces caused due to chemical bonding or/and electrostatic attraction and van der Waals forces. The system strength is determined by the interfacial forces as well as by the mechanical behavior of interfacial zone and two different phases of huge mass. Fundamentally, there are two principal adhesive bonding arises viz: structural and non-structural.

\subsection{Structural Adhesive Bonding}

A large stress up to their yield point produced by the objects used for bonding i.e., adherends [3]. There must be durability of bond throughout lifetime with shear strength more than $7 \mathrm{MPa}$.

\subsection{Nonstructural Adhesives Bonding}

It holds lightweight equipment rather than extensive loads. This is also called as holding adhesive. E.g.: Packaging adhesives, Pressure-sensitive tapes.

\section{Functions of Adhesives}

Mutually join the parts is the primary function of an adhesive. The goal is accomplished using stresses from one member to another by transmission which is distributed consistently and can be achieved with mechanical fasteners. The structural strength is restricted to area of members in contact with fasteners during mechanical fastening [4, 3251]. Obtaining stronger adhesive bonds than adherents is not at all a strange. Formation of smooth surfaces is natural benefit of joined structures using adhesives. Helicopter rotor blade in aerospace, involve smooth externals to minimize trail and keep temperature possibly low. Rather than the conventional bonding the adhesive bonding builds consistent distribution of stresses in the joint using lighter weight equipment in which the strength and rigidity of adherends consumed entirely [4]. A larger area is provided by adhesive bonding for overall stress transfer, which causes decline in the concentration of stress in the compact region. Profound loads are imposed during adhesive joints on adherends during heating or welding. Adherends are comparatively liberated from deformation via movement of heat-influence [4].

\section{Adhesives Categorization}

Based upon chemical structure or functionality, adhesives 
materials can be classified as natural and artificial adhesives. The natural adhesives are animal glue, adhesives of proteins and naturally occurring rubbers etc. Some examples of artificial adhesives are industrial (i.e. acrylics, epoxy derivatives, silicones etc.) and special compounds (i.e. stress dependent adhesives).

\section{Benefit and Drawbacks of Adhesive Joining}

\subsection{Benefits [5-6]}

(a). Equal stress liberation and more stress carrying region.

(b). Joins thick or narrow equipment of variable configuration.

(c). Joins homogenous or heterogeneous equipment.

(d). Joins with horizontal contours.

(e). Protection from heat transfer and electrical conductance.

(f). Supplies striking strength/weight ratio.

(g). Cheaper and quicker as compared to mechanical fastening technique.

\subsection{Drawbacks [5-7]}

(a). Imaginary assessment of bonds is not allowed unless adherends are transparent.

(b). A vigilant surface is required to get bonds durability.

(c). Mainly the areas where higher alleviated temperatures are not used there is a need of longer cure time.

(d). Other fastening process are required for holding fixtures, presses, ovens, and autoclaves.

(e). Temperatures are restricted to $177^{\circ} \mathrm{C}$ in maximum cases, but usually for more expensive adhesives the limitation is up to $371^{\circ} \mathrm{C}$.

(f). Environmental condition (at which it is exposed) is a major factor deciding durability of adhesives.

(g). Solvents applied in binding may create several health hazards.

\section{Requirements for Excellent Bonding [6]}

There is a necessity of superior bonding using adhesives, for analytic technique, procedure of quality control and bonding too. These comprise:

(a). Appropriate selection of adhesive.

(b). Superior design for joint.

(c). Surfaces cleansing.

(d). Wetted bonded surfaces.

(e). Suitable procedure for adhesive bonding.

\subsection{Appropriate Selection of Adhesive}

Due to the higher availability of a number of adhesives for joint the choice becomes an important criteria depends upon adherends personality, performance of used last part and adhesive joining procedure.

\subsection{Superior Design for Joining}

By designing cautiously the potency of joint may express. A stronger bond may be generated by combining mechanical sketching with adhesive bonding [8].

\subsection{Surface Cleansing}

Applying clean adherends surface, an excellent adhesive bond may be obtained. Foreign materials, like dust, lubricant, damp and frail oxide covers should be detached from surfaces because these feeble boundary covers are pledged by adhesives rather than the substrates [9].

\subsection{Wetting}

The disarticulation of air from adherends surfaces by liquid is wetting. An excellent wetting creates superior region for connection among adherends and adhesives [10].

\subsection{Suitable Procedure for Adhesive Bonding}

Exposure of adhesives must be in temperature, pressure and grip time not only functional to adherends surfaces. There is a requirement of conversion of liquid adhesive into solid via any of three ways mentioned below [6].

(a). Chemical reaction via blend of one i.e. warmth, stress with remedial agent.

(b). Cooling from melt fluid.

(c). Ventilation after solvent disappearance.

\section{Theories of Adhesion [11]}

Traditionally postulated theories for adhesion mechanisms are mentioned as:

(a). Mechanical interlocking.

(b). Electrostatic.

(c). Diffusion.

(d). Adsorption/Surface reaction.

More recent theories developed are mentioned as:

(e). Chemical bonding.

(f). Weak boundary layer and some theories on the scale of various actions are namely as:

(i). Microscopic.

(ii). Macroscopic.

(iii). Molecular.

(iv). Atomic.

\subsection{Theory of Mechanical Interlocking}

The hypothesis reveals the penetration of adhesives into pore, cavity and irregularity on the substrate surface via displacement of targeted air from the boundary due to which adhesion phenomenon takes place.

There is quick stronger bond formation onto porous abraded surface than smooth surface. It is not universally functionalized though there is a fine adhesion amid flat facets.

Abraded facet exhibits good bonding is due to the 
following reasons are mentioned as:

(1). Mechanical interlocking.

(2). Hygienic facade.

(3). Development of extremely rash surface.

(4). An augmentation in connective facade surrounding area [12-13].

There is appreciative information in articles which correlates potency of joining and strength of bonding to improved surface coarseness [14].

\subsection{Electrostatic Theory}

The hypothesis reveals the occurrence of adhesion phenomenon because of electrostatic property among adhesive-adherends [15-18] via the movement of an electron. A twofold coating is formed electrically at boundary of adhesive-adherend using electrostatic forces which resist separation [13]. This is a conceivable mechanism for polymers and metals adhesion [19-20].

\subsection{Theory of Diffusion}

The hypothesis explain the occurrence of adhesion phenomenon via expansion of inter diffusion of molecules among adhesive and adherends. The theory principally applied in case of both polymeric adhesive-adherends with longer fragment with competence of movement. Usually width of diffuse interfacial coating varies from 10-1,000 $\AA$ $(1-100 \mathrm{~nm})$ [13]. Cohesive energy density (CED) is applied to interpret diffusion bonding.

$$
\mathrm{CED}=\mathrm{Ecoh} / \mathrm{V}
$$

Where,

Ecoh = Essential amount of energy for molecules separation to an infinite distance.

$\mathrm{V}=$ Molar volume.

$\mathrm{D}=$ Solubility parameter.

\subsection{Theory of Wetting}

The hypothesis exhibits that due to molecular connection between two i.e., equipment and surface, forces need to expand and the adhesion occurred. Initially bond is form to develop interfacial forces among adhesive and substrates. The procedure of regular contact amid adhesive and adherends is called "wetting". There must be indeed a lower surface tension of adhesives than the decisive solid surface tension to damp a concrete facade. This is specifically motivation for treating plastic surfaces, which raises their facade power and polarization. The forces of Van der Waals are enormously susceptible to distance (r) amid fragments, declining by seventh power inverse $(1 / \mathrm{r} .7)$ of detachment amid two fragments and power distance in cubic among two adherends. There is a very good demonstration in (Figure 1) of absolute and partial adhesive wetting getting dispersed onto facade. Adhesive pass into valleys on facade surfaces is resulted from good wetting. The outcome of poor wetting is bridging of adhesive over valley and causing diminution of definite connection area among adhesive-adherends, consequentially there is an inferior joining potency [13].

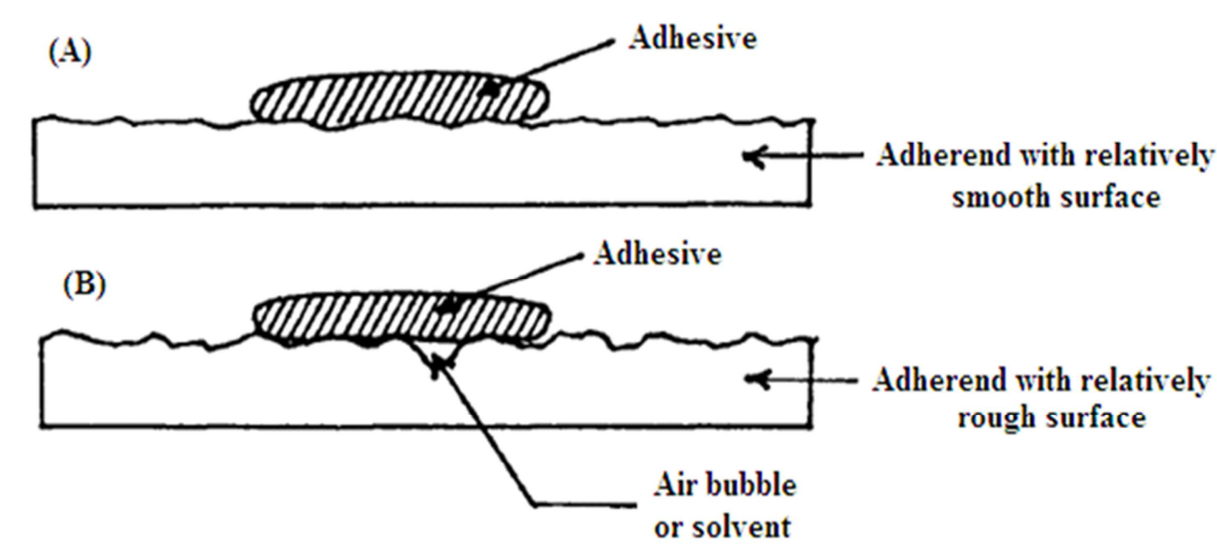

Figure 1. Examples revealing (a) superior and (b) inferior wetting of facade by dispersion of an adhesive [13].

\subsection{Chemical Bonding}

The hypothesis assigns the creation of adhesion bonding onto the facade via chemically. Hydrogen, covalent and ionic bonding among adhesive and adherends formed and are more potential than attractive forces of dispersion.

Generally, four kinds of interactions occur during chemical bonding: covalent bonds, hydrogen bonds, Lifshitz-vander Waals forces and acid-base interactions.

\subsubsection{Covalent and Ionic Bonds}

In case of chemical bonding shows advanced bonding or adhesion ethics than other forces. Weaker physical forces are caused by secondary valence bonding. These forces are widespread in polar group like carboxylic acid than non-polar groups like polyolefins.

\subsubsection{Dipole-Dipole Interaction}

Intermolecular interaction resulted from fragment with polar group to align them like positive ending of one fragment is nearer to the negative of other.

\subsubsection{Hydrogen Bonding}

An exclusive dipole-dipole interaction occurs when $\mathrm{H}$ atom is bonded to tiny and extremely electro negatively charged atom i.e. fluorine, oxygen, nitrogen or sulphur. 


\subsubsection{London Dispersion Forces}

Small and instant dipoles occur due to change in the position of electrons onto the nuclei throughout their movement caused by intermolecular forces.

\subsubsection{Covalent Chemical Bonds}

Interface in adhesives occurs with cross-linked structures and thermoset coatings. The bond is the strongest with maximum durability and involves reactive chemical groups. E.g. formerly layered facade, timber and few polymers that hold diverse functional groups below suitable circumstances generate chemical bonding by means of adhesives.

\subsubsection{Acid-Base Theory}

Based upon Lewis acid and base theory, a new kind of acid-base interaction is discovered recently. According to Lewis "acid is a material which can take an electron pair from base e.g. $\mathrm{BF} 3, \mathrm{SiO}_{2}$ and base is a substance which can give an electron pair e.g. $\mathrm{NH}_{3}, \mathrm{PH}_{3}, \mathrm{C}_{6} \mathrm{H}_{5} \mathrm{C}_{2} \mathrm{NH}_{2}$ " [21]. Based upon this theory, adhesion phenomenon causes due to attraction of polar groups of Lewis acids and bases at the boundary. The hypothesis is cited in few articles [22-27]. The strength of hydrogen bond is inferior to ionic and covalent bond is noteworthy amid secondary interactions [28-29]. The outcome is the correlation among electron donating compounds and ability to accept form the fundamental of adhesion via acid-base theory.

\subsection{Theory of Weak Boundary Layer}

The hypothesis explains failure at boundary the bond failure is due to either break of cohesive or by the feeble cover of boundary [30]. Origin of feeble cover boundary may be due to adhesive-adherends and circumstances or via blending of these due to occurrence of impurities in adhesive or adherends near to bonding surface. E.g. polyethylene and metal oxides. The weak boundary film in polyethylene at interface participates to inferior stress when applied as an adhesive or an adherends. Breakdown of adhesive joints occurs cohesively within the oxide due to weakly linkage of metal oxides with base metals. As revealed in (Figure 2), when the substrate is not wetted by an adhesive a feeble cover around boundary generates i.e., at the boundary air is fascinated, causing diminution in the potency of joints $[13,32-51]$.

\section{Bond Failure Modes}

A bonding via adhesion is hypothetically revealed in (Figure 2). Supposing the bond is accessed via tensile strength in which two adherends are dragged perpendicular to the bond. There is diverse feasibility for origin of failure. The surface implicated in bond failure is known as locus of failure. If bond failure arises between adhesive layer and adherends, it is termed as adhesive failure as exposed in (Figure 2(a)). A disjointing phenomenon after breakdown in which both-adherends facades remains enclosed with adhesive is entitled as cohesive breakdown/failure as revealed in (Figure 2(b)). Occasionally adhesive bond is very much strong so the failure happens in one of adherends far from bond, called cohesive failure in adherends as shown in (Figure 2(c)). Sometimes failure of bond includes more than one breakdown form and attributed as percentage to cohesive or adhesive breakdown/failure. The portion of connective facade region that failed/breakdown cohesively or adhesively is the deliberation of percentage breakdown.

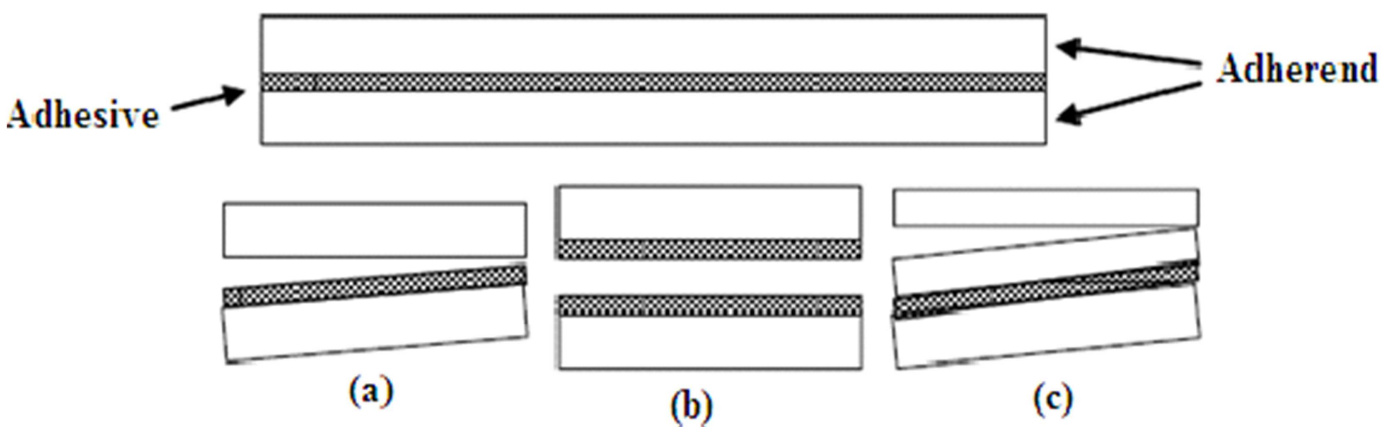

Figure 2. Presentation of failure modes of adhesive bond: (a) failure of adhesive (b) failure of cohesive in the layer of adhesive (c) failure of cohesive in adherends.

\section{Mechanism of Bond Failure/Breakdown}

Adhesive joining breaking may occur adhesively or cohesively. Breakdown of an adhesive exists interracially among adhesive and adherends. A cover of adhesive is permitted to stay on either facade as a result of cohesive failure/breakdown. Failure of adherends prior to the adhesive is called as a "cohesive failure". A number of approaches of failure are revealed in (Figure 2). During analysis of an adhesive joint testing for destruction, the failure mode is frequently articulated as percentage cohesive or adhesive breakdown/failure as exposed in (Figure 2). 100\% cohesive breakdown is ideal breakdown of adhesion cover. Combination of few adhesive-adherends may be unsuccessed, however display superior potency over weaker adhesive with parallel joining which breaks cohesively. The more important criterion is vital strength of joint than the mode of failure of joint. To adjust the thermal expansion characteristics and limit internal stresses of adhesives generally, fillers are applied. Another, method to hold these 
stresses is using elastic adhesives. Significant factors to determine the durability of bond is the action of stress on concluded joints, their route to adhesive and speeds at which it is functional. Continuous loads can cause premature failure. Few adhesives break rapidly under dead load, mainly after exposing heat or moisture. Various adhesives are responsive to the speed at which the joint is stressed. An excellent tensile or shear strength is shown by rigid, brittle adhesives but with inferior potency. Adhesive joints can be degraded via several environmental factors in different manners. If there is maximum component of environment i.e., warmth and damp, causes a synergistic effect for diminishing the strength of adhesive after their blending.

\section{References}

[1] Modified from ASTM D 907-82, Standard Definitions of Terms Relating to Adhesives, published in Volume 15.06Adhesives, 1984 Annual Book of ASTM Standards.

[2] Wu, S., Polymer Interface and Adhesion, 1st ed., Marcel Dekker, New York, 1982.

[3] Mittal, K. L., Adhesive Joints: Formation, Characteristics and Testing, Brill Academic Publishers, Netherlands, 2003.

[4] Staff written, Joining techniques. Section 4, Machine Design, Fastening and Joining Reference Issue, 48(26): 155-162, 1976.

[5] Sharpe, L. H., The materials, processes and design methods for assembly with adhesives. Machine Design, 38(19): 179200, 1966.

[6] Petrie, E. M., Plastic and elastomer adhesives (Chapter 7). Handbook of Plastics and Elastomers (C. A. Harper, ed.), McGraw-Hill, New York, 1996.

[7] De Lollis, N. J., Adhesives for Metals-Theory and Technology, Industrial Press, New York, 1970.

[8] Handbook of Plastics Joining, Plastics Design Library, William Andrew Publishing, Norwich, NY, 1997.

[9] Ebnesajjad, S. and Ebnesajjad, C. F. Surface Preparation Techniques for Adhesive Bonding, William Andrew Publishing/Noyes, Norwich, NY, 2006.

[10] Satas, D. and Tracton, A. A. eds., Coatings Technology Handbook, 2nd ed., Marcel Dekker, New York, NY, 2001.

[11] Lee, L. H., Fundamentals of Adhesion, Plenum Press, New York, 2001.

[12] DeMejo, L. P., Rimai, D. S., Sharpe, L. H. eds., Fundamentals of Adhesion and Interfaces, Taylor \& Francis, London, 1999.

[13] Petrie, E. M., Plastics and adhesives as adhesives. Handbook of Plastics and Elastomers (C. A. Harper, ed.), 4th ed., McGraw-Hill, New York, 2002.

[14] Allen, K. W., Int. J. Adhes., 13: 67, 1993.

[15] Deraguin, B. V., Smilga, V. P. J. Appl. Phys., 38: 4609, 1967.

[16] Deraguin, B. V. Toporov, Y. P., Physiochem. Aspects Polym. Proc. Int. Symp., 2, p. 605, 1983.
[17] Cross, J. A., Surface Contamination: Its Genesis, Detection and Control (Mittal, K. L. ed.), Vol. 2, p. 89, Plenum Press, New York, 1979.

[18] Possart, W., Int. J. Adhes., 8: 77, 1988.

[19] Roberts, A. D., J. Phys. D., 10: 1801, 1977.

[20] Roberts, A. D., Adhesion, 1: 207, 1977.

[21] Parker, S. P., ed., Encyclopedia of Chemistry, $2^{\text {nd }}$ ed., McGraw-Hill, Inc., New York, 1992.

[22] Fowkes, F. M., Acid-base interactions in polymer adhesion. Physicochemical Aspects of Polymers Surfaces (Mittal, K. L. ed.), Vol. 2, Plenum Press, New York, 1983.

[23] Fowkes, F. M., Attractive forces at solid-liquid interface. Wetting, SCI Monograph No. 25, London, 1967.

[24] Fowkes, F. M., Maruchi, S., Org. Coat. Plast. Chem. Prep., 37: $605,1977$.

[25] Fowkes, F. M., Mostafa, M. A., Ind. Eng. Chem., Prod. Res. Dev., 17: 3, 1978.

[26] Gutmann, V., Donor-Acceptor Approach to Molecular Interaction, Plenum Press, New York, 1978.

[27] Bolger, J. C., Michaels, A. S., Molecular structure and electrostatic interaction of polymer-solid interface. Interface Conversion for Polymer Coatings (P. Weiss and G. Dale Cheever, eds.), Elsevier, New York, 1968.

[28] Douglas, B., McDaniel, D. H., Alexander, J. J., Concepts and Models of Inorganic Chemistry, 2nd ed., John Wiley \& Sons, Inc., New York, 1983.

[29] Mittal, K. L., Adhesion Measurement of Films and Coatings, Vol. 2, Brill Academic Publishers, Netherlands, 2001.

[30] Bikerman, J. J., Causes of poor adhesion. Indus. Eng. Chem., 59(9), 40-44, 1967.

[31] Mittal, K. L., Lee, K. W., Polymer Surfaces and Interfaces: Characterization, Modifi cation and Applications, VSP, Utrecht, Netherlands, 1997.

[32] Mandolfino, C., Pizzorni, M., Duraility of polyamide bonded joints: influence of surface pre-treatment, Int. $\mathrm{J}$ of Adh.andAdh., http://doi.org/10.1016/ijadhadh.2018.08.002.

[33] Budhe, S., Da Silva, L. F. M., An updated review of adhesively bonded joints in composite materials, Int. J of Adh. andAdh., http://doi.org/10.1016/ijadhadh.2016.10.010.

[34] Staudt, Y., Schneider, J., Failure behaviour of silicone adhesive in bonded connection with simple geometry, Int. J of Adh. and Adh., http://doi.org/10.1016/ijadhadh.2017.12.015.

[35] Belnoue, J. P. H., Hallett, S. R., Cohesive/adhesive failure interaction in ductile adhesive joint parts I: A smeared-crack model for cohesive failure, Int. J of Adh. andAdh., http://doi.org/10.1016/ijadhadh.2016.03.009.

[36] He, X., A review of finite element analysis of adhesively bonded joints, Int. J of Adh. and Adh., http://doi.org/10.1016/ijadhadh.2011.01.006.

[37] Ji, X., Guo, M., Preparation and properties of a chitosen-lignin wood adhesive, Int. $\mathrm{J}$ of Adh. andAdh., http://doi.org/10.1016/ijadhadh.2017.12.005. 
[38] Heidarpour, F., Farahani, M., Ghabezi, P., Experimental investigation of the effects of adhesive defects on the single lap joint strength, Int. J of Adh. andAdh., http://doi.org/10.1016/ijadhadh.2017.08.005.

[39] Da Silva, L. F. M., Das Neves, P. J. C., Adams, R. D., Spelt, J. K., Analytical model of adhesively bonded joints-Part I: Literature survey, Int. J of Adh. and Adh., http://doi.org/10.1016/ijadhadh.2008.06.005.

[40] Figueiredo, J. C. P., Da Silva, L. F. M., Adhesive thickness influence on the shear fracture toughness measurements of adhesive joints, Int. J of Adh. andAdh., http://doi.org/10.1016/ijadhadh.2018.02.015.

[41] Packham, D. E., Surface energy, surface topography and adhesion, Int. J of Adh. andAdh., http://doi.org/10.1016/S0143-7496(03)00068-X.

[42] Zhang, C., Liu, W., Adhesion properties of atactic polypropylene/acrylate blend copolymer and its adhesion mechanism for untreated polypropylene materials, Int. J of Adh. andAdh., http://doi.org/10.1016/ijadhadh.2017.09.007.

[43] Cabral-Fonseca, S., Sousa, J., Durability of FRP - concrete bonded joints in structural rehabilitation: A review, Int. J of Adh. andAdh., http://doi.org/10.1016/ijadhadh.2018.02.014.

[44] Sun, S., Liu, A., A review on mechanical properties of pressure sensitive adhesives, Int. J of Adh. andAdh., http://doi.org/10.1016/ijadhadh.2012.10.011.
[45] Baldan, A., Adhesion phenomena in bonded joints, Int. J of Adh. and Adh., http://doi.org/10.1016/ijadhadh.2012.04.007.

[46] Barry, C.P., Hansen, C.J., The identification and screening of lower toxicity solvents for contact adhesives, Int. J of Adh. andAdh., http://doi.org/10.1016/ijadhadh.2017.06.022.

[47] Razavi, S. M. J., Khoramishad, H., Single lap joints bonded with structural adhesives reinforced with a mixture of silica nanoparticles and multi walled carbon nanotubes, Int. $\mathrm{J}$ of Adh. andAdh., http://doi.org/10.1016/ijadhadh.2017.10.007.

[48] Moya-Sanz, E. M., Garcia-Castillo, S. K., Effect of the geometry in the strength of single-lap adhesive joints of composites laminates under uniaxial tensile load, Int. J of Adh. andAdh., http://doi.org/10.1016/ijadhadh.2016.10.009.

[49] Molitor, P., Barron, V., Young, T., Surface treatment of titanium for adhesive bonding to polymer composites: A review, Int. J of Adh. andAdh., http://doi.org/10.1016/S01437496(00)00044-0.

[50] Park, Y. J., Sung, I. K., UV- and thermal-curring behaviours of dual-curable adhesives based on epoxy acrylate oligomers, Int. $\mathrm{J}$ of Adh. and Adh. http://doi.org/10.1016/ijadhadh.2009.02.001.

[51] Jumbo, F. S., Wahab, M. M. A., Thermal residual stress analysis of epoxy bi-material laminates and bonded joints, Int. $\mathrm{J}$ of Adh. and Adh. http://doi.org/10.1016/ijadhadh.2010.03.009. 